\title{
Cerebrospinal fluid-based kinetic biomarkers of axonal transport in monitoring neurodegeneration
}

\author{
Patrizia Fanara, ${ }^{1}$ Po-Yin A. Wong, ${ }^{1}$ Kristofor H. Husted, ${ }^{1}$ Shanshan Liu, ${ }^{1}$ Victoria M. Liu, ${ }^{1}$ \\ Lori A. Kohlstaedt, ${ }^{2}$ Timothy Riiff, ${ }^{1}$ Joan C. Protasio, ${ }^{1}$ Drina Boban, ${ }^{1}$ Salena Killion, ${ }^{1}$ Maudi Killian, ${ }^{3}$ \\ Lorrie Epling, ${ }^{3}$ Elisabeth Sinclair, ${ }^{3}$ Julia Peterson, ${ }^{4}$ Richard W. Price, ${ }^{4}$ Deborah E. Cabin, ${ }^{5}$ \\ Robert L. Nussbaum, ${ }^{6}$ Jörg Brühmann, 7 Roland Brandt, ${ }^{7}$ Chadwick W. Christine, ${ }^{4}$ \\ Michael J. Aminoff, ${ }^{4}$ and Marc K. Hellerstein 8,9
}

\begin{abstract}
${ }^{1}$ KineMed Inc., Emeryville, California, USA. ${ }^{2}$ Proteomics/Mass Spectrometry Laboratory, University of California at Berkeley, Berkeley, California, USA. ${ }^{3}$ Division of Experimental Medicine, Department of Medicine, and 4 Department of Neurology, UCSF, San Francisco, California, USA. 5McLaughlin Research Institute, Great Falls, Montana, USA. ${ }^{\circ}$ Department of Medicine and UCSF Institute for Human Genetics, UCSF, San Francisco, California, USA. ${ }^{7}$ Department of Neurobiology, University of Osnabruck, Osnabruck, Germany. ${ }^{8}$ Department of Nutritional Sciences and Toxicology, University of California at Berkeley, Berkeley, California, USA. ${ }^{9}$ Department of Medicine, UCSF, San Francisco General Hospital,
\end{abstract} San Francisco, California, USA.

\begin{abstract}
Progress in neurodegenerative disease research is hampered by the lack of biomarkers of neuronal dysfunction. We here identified a class of cerebrospinal fluid-based (CSF-based) kinetic biomarkers that reflect altered neuronal transport of protein cargo, a common feature of neurodegeneration. After a pulse administration of heavy water $\left({ }^{2} \mathrm{H}_{2} \mathrm{O}\right)$, distinct, newly synthesized ${ }^{2} \mathrm{H}$-labeled neuronal proteins were transported to nerve terminals and secreted, and then appeared in CSF. In 3 mouse models of neurodegeneration, distinct ${ }^{2} \mathrm{H}$-cargo proteins displayed delayed appearance and disappearance kinetics in the CSF, suggestive of aberrant transport kinetics. Microtubule-modulating pharmacotherapy normalized CSF-based kinetics of affected ${ }^{2} \mathrm{H}$-cargo proteins and ameliorated neurodegenerative symptoms in mice. After ${ }^{2} \mathrm{H}_{2} \mathrm{O}$ labeling, similar neuronal transport deficits were observed in CSF of patients with Parkinson's disease (PD) compared with non-PD control subjects, which indicates that these biomarkers are translatable and relevant to human disease. Measurement of transport kinetics may provide a sensitive method to monitor progression of neurodegeneration and treatment effects.
\end{abstract}

\section{Introduction}

Biomarkers that provide insight into the pathophysiology, progression, and treatment response of neurodegenerative diseases would represent a major advance for disease research, clinical management, and drug development. Currently, in the absence of such biomarkers, survival, symptoms, or nonspecific outcome measures are used as indicators of disease progression and treatment efficacy for clinical and investigative purposes. Survival studies and other clinical outcomes of low specificity, however, are affected by factors besides disease-modifying therapies and require large number of subjects to show effects in clinical trials (1).

Disturbances of neuronal transport have been suggested as potential causal factors in Alzheimer's disease (AD), Parkinson's disease (PD), Huntington's disease (HD), and amyotrophic lateral sclerosis (ALS) (2-12). Data from cell cultures and preclinical models suggest that abnormal microtubule (MT) dynamics and MT-based neuronal transport may play a role (2-19). The recent development of an in vivo stable isotope-mass spectrometric technique for measuring the turnover of MTs provides insights regarding neurodegeneration (14-17). The measure-

Conflict of interest: Drina Boban, Joan C. Protasio, Kristofor H. Husted, Patrizia Fanara, Po-Yin A. Wong, Salena Killion, Shanshan Liu, Timothy Riiff, and Victoria M. Liu are employees of KineMed Inc.; many or all own stock in the company. Marc K. Hellerstein owns stock in, is on the Scientific Advisory Board of, and receives consulting income from KineMed Inc. Roland Brandt serves as a scientific advisor for and owns stock in KineMed Inc.

Citation for this article: J Clin Invest. 2012;122(9):3159-3169. doi:10.1172/JCI64575. ments revealed that hyperdynamic MTs underlie impairment of MT-based axonal transport in mice expressing the ALS-linked mutant $S O D 1^{193 A}(15)$ and cognitive deficits in $\mathrm{AD}$ mice or other models of neurodegeneration $(16,17)$. Moreover, MT-modulating pharmacotherapy proved effective at delaying disease progression and increasing neuronal survival (15-17).

Because measurement of MT turnover requires neuronal tissue, translation into human studies was not possible. Here, we describe a method for measuring the efficiency of axonal transport in the CNS of living animals and humans, based on sampling and analyzing cerebrospinal fluid (CSF) after in vivo metabolic labeling.

Axonal transport ensures rapid delivery of biosynthetic products (e.g., cargo proteins) and organelles (e.g., mitochondria) to their correct destination, which is fundamental for normal function of synapses. Cargo vesicles within neurites are known to move along the MT tracks via molecular motors, such as dynein and kinesin, which connect vesicles with MTs while propelling the vesicle in an ATP-dependent manner in either anterograde or retrograde directions (20).

Newly synthesized cargo proteins destined for secretion travel from the cell bodies of neurons, where they are primarily produced, to the nerve terminals where they are released into the extracellular fluid (EF) and eventually reach the CSF, which is in steady state with the EF (21). Cargo may be sampled in CSF (22). Accordingly, we hypothesized that the timing of appearance and disappearance of newly synthesized ${ }^{2} \mathrm{H}$-labeled neuronal cargo proteins in CSF, after in vivo metabolic labeling, will reflect the 
A
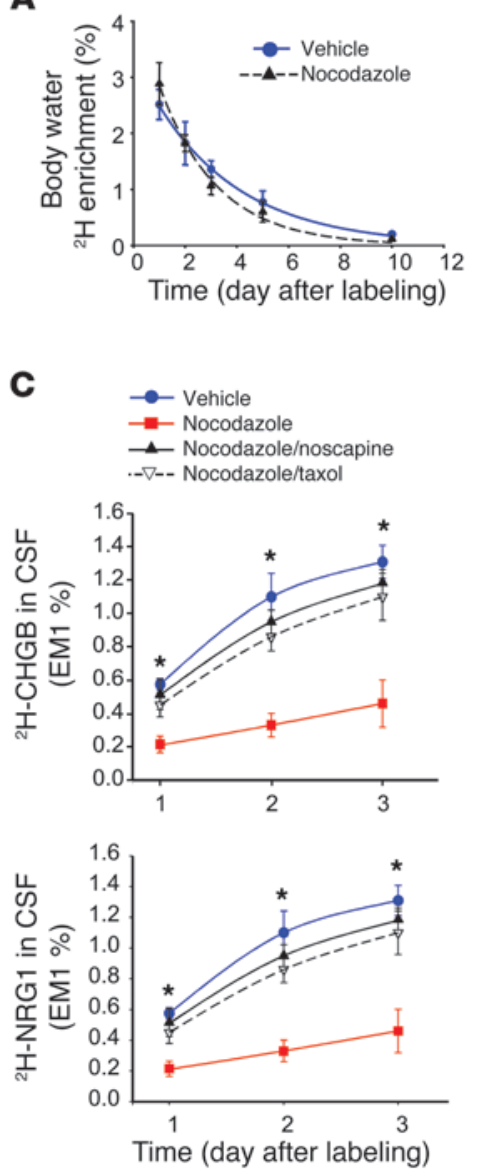

B
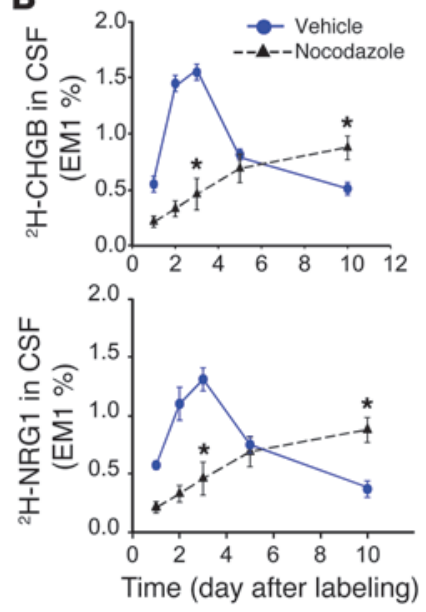

D
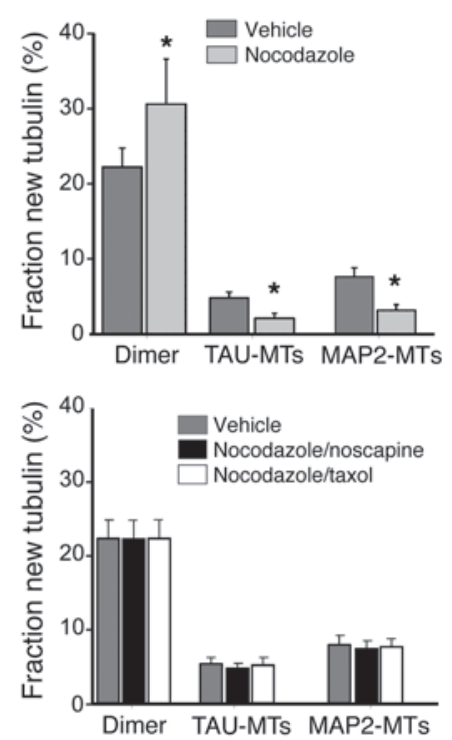

\section{Figure 1}

Effects of nocodazole on CSF-based secretion kinetics of neuronal cargo proteins and on MT turnover in mice. (A) Decline in plasma body water ${ }^{2} \mathrm{H}$ enrichment $(n=10$ per time point in duplicate; mean $\pm S D$ ). Body water decay curves did not differ between nocodazole-infused mice and vehicle controls. Body water ${ }^{2} \mathrm{H}_{2} \mathrm{O}$ content decayed to low levels by 3-5 days after bolus injection. (B) Delays in the time of appearance, $T_{\max }$, and disappearance of ${ }^{2} \mathrm{H}-\mathrm{CHGB}$ and ${ }^{2} \mathrm{H}-\mathrm{NRG} 1$ were observed in CSF from nocodazole-infused mice compared with vehicle controls $(n=10$ per time point in duplicate; mean $\pm \mathrm{SD}$ ). CSF was collected 1, 2, 3, 5, and 10 days after labeling. ${ }^{2} \mathrm{H}-\mathrm{CHGB}$ and ${ }^{2} \mathrm{H}-\mathrm{NRG} 1$ were sequentially immunoprecipitated and purified to homogeneity from albumin/lg-depleted CSF. ${ }^{\star} P<0.001$. (C) CSF-based secretion kinetics of ${ }^{2} \mathrm{H}-\mathrm{CHGB}$ and ${ }^{2} \mathrm{H}-\mathrm{NRG} 1$ in vehicle-infused, nocodazole-infused, nocodazole/noscapine-treated, and nocodazole/taxol-treated mice (mean \pm SD). Treatment with noscapine and taxol normalized MT-mediated transport rates of ${ }^{2} \mathrm{H}-\mathrm{CHGB}$ and ${ }^{2} \mathrm{H}-\mathrm{NRG} 1$ to the levels observed in CSF of age-matched vehicle controls. ${ }^{*} P<0.001$. (D) ${ }^{2} \mathrm{H}$-label incorporation of hippocampal tubulin in dimers and MTs $(n=4$ per group; 10-week-old males, mean $\pm \mathrm{SD}$ ). In nocodazoleinfused mice, an increase in ${ }^{2} \mathrm{H}$-free tubulin dimers correlated with a reduction in ${ }^{2} \mathrm{H}$-labeling of MTs associated with TAU and MAP2. The nocodazole/noscapine and nocodazole/taxol treatment groups showed ${ }^{2} \mathrm{H}$-labeling of TAU- and MAP2associated MTs similar to vehicle controls. ${ }^{*} P<0.001$. kinetics of MT-based transport of neuronal vesicular cargo proteins, assuming there is no change in protein clearance from the CSF. The procedure that has been developed for measuring appearance/disappearance kinetics of cargo proteins into CSF is simple and safe, involving administration of a pulse dose of a nonradioactive, stable isotope-labeled tracer such as heavy water $\left({ }^{2} \mathrm{H}_{2} \mathrm{O}\right)$, followed by CSF sampling through lumbar puncture (LP) and gas chromatographic/mass spectrometric (GC/MS) analysis of label content in selected cargo proteins.

We have measured the kinetics of appearance in and disappearance from CSF for several cargo proteins carried via secretory vesicles in neurons (23-31), including chromogranin-B (CHGB), $\alpha$-synuclein (SNCA), neuregulin-1 (NRG1), and the nonamyloidogenic N-terminal fragment of amyloid precursor protein $(\operatorname{sAPP} \alpha)$. We first compared CSF transport kinetics of healthy mice with those of mice infused with the MT-depolymerizing drug nocodazole (16), of symptomatic SOD $1^{\mathrm{G} 93 A}$ mice $(15,30)$, and of mice injected with 1-methyl-4-phenyl-1,2,3,6-tetrahydropyridine (MPTP) $(13,19,32,33)$. We then determined the effects of MTstabilizing pharmacotherapy on altered CSF-based kinetics of neuronal cargo proteins in these models.
Finally, kinetics of the same cargo proteins were determined in the CSF of 6 non-PD control human subjects and 12 symptomatic $\mathrm{PD}$ patients. Marked alterations in neuronal ${ }^{2} \mathrm{H}$-cargo kinetics were observed in CSF from PD patients. These data indicated that CSF kinetic biomarkers of axonal transport provide direct in vivo metrics of neurodegeneration that are translatable in humans.

\section{Results}

Altered kinetics of neuronal transport in CSF of murine models of neurodegeneration. To evaluate in CSF the time of appearance of secreted neuronal cargo proteins as biomarkers of axonal transport, we used a pulse-chase ${ }^{2} \mathrm{H}_{2} \mathrm{O}$ labeling protocol in mice. This labeling paradigm allows highly labeled proteins synthesized over the first approximately 48-72 hours of label exposure to be monitored as they appear in and disappear from CSF (Figure 1A). Cargo proteins were selected on the basis of the following published criteria: (a) high expression in neurons; (b) presence in CSF (Table 1); and (c) association with neurodegeneration and neuronal survival (11-13, 22-31).

To test whether changes in MT dynamics are causally involved in altered kinetics of axonal transport, we infused mice with 
Table 1

Level of cargo molecules in murine CSF

\begin{tabular}{|c|c|c|}
\hline $\begin{array}{l}\text { Albumin/Ig- } \\
\text { depleted CSF }\end{array}$ & $\begin{array}{l}\text { Total protein } \\
\text { (ng/ml) }\end{array}$ & $\begin{array}{c}\text { Total cargo protein } \\
(\mathrm{ng} / \mathrm{ml})\end{array}$ \\
\hline \multicolumn{3}{|l|}{ CHGB } \\
\hline WT & $41,200-51,400$ & $3.2 \pm 0.7$ \\
\hline Vehicle injection & $41,200-51,400$ & $4.3 \pm 0.6$ \\
\hline Nocodazole injection & 51,000 & $2.2 \pm 0.6$ \\
\hline MPTP injection & 50,700 & $2.8 \pm 0.8$ \\
\hline SOD1G93A & 39,600 & $1.8 \pm 0.4$ \\
\hline \multicolumn{3}{|l|}{ NRG1 } \\
\hline WT & $37,800-46,700$ & $3.5 \pm 0.4$ \\
\hline Vehicle injection & $37,800-46,700$ & $4.1 \pm 0.9$ \\
\hline Nocodazole injection & 45,300 & $2.8 \pm 0.7$ \\
\hline MPTP injection & 45,200 & $2.3 \pm 0.5$ \\
\hline SOD1G93A & 36,700 & $2.6 \pm 0.6$ \\
\hline \multicolumn{3}{|l|}{ sAPP $\alpha$} \\
\hline WT & $32,000-41,500$ & $5.5 \pm 0.7$ \\
\hline Vehicle injection & $32,000-41,500$ & $6.1 \pm 0.8$ \\
\hline Nocodazole injection & 39,000 & $3.8 \pm 0.5$ \\
\hline MPTP injection & 38,300 & $4.3 \pm 0.7$ \\
\hline SOD1G93A & 30,700 & $5.8 \pm 0.6$ \\
\hline \multicolumn{3}{|l|}{ SNCA } \\
\hline WT & $26,300-35,000$ & $0.8 \pm 0.7$ \\
\hline Vehicle injection & $26,300-35,000$ & $1.1 \pm 0.9$ \\
\hline Nocodazole injection & 32,200 & $0.5 \pm 0.6$ \\
\hline MPTP injection & 31,400 & $0.3 \pm 0.7$ \\
\hline SOD1G93A & 25,900 & $0.2 \pm 0.4$ \\
\hline
\end{tabular}

Values represent mean \pm SD of 3 replicates ( $n=10$ per group). Total protein decreased after sequential immunoprecipitation of each secreted cargo molecule. The percentage of secreted cargo proteins removed from CSF samples by preincubation with antibody beads was $90 \%-95 \%$ for each, as quantitated by ELISA. nocodazole, a MT-depolymerizing agent, 1 day before CSF sampling. Measurement of newly synthesized ${ }^{2} \mathrm{H}-\mathrm{CHGB}$ and ${ }^{2} \mathrm{H}-\mathrm{NRG} 1$ in CSF from nocodazole-infused mice revealed major delays compared with vehicle-treated controls (Figure 1B). In vehicle-treated mice, the times of first appearance (day 1 or 2$)$, peak $\left(T_{\max }\right.$; day 3 ), and disappearance (days 5-10) were markedly earlier than in nocodazole-treated mice. Similar changes in CSF secretion kinetics were observed for other axonally transported cargo, ${ }^{2} \mathrm{H}$-SNCA and ${ }^{2} \mathrm{H}$-sAPP $\alpha$, in nocodazole-treated mice (Supplemental Figure 1A; supplemental material available online with this article; doi:10.1172/JCI64575DS1). Amyloid precursor protein is expressed in adult $\mathrm{CNS}$, and its processing is known to generate the sAPP $\alpha$ fragment, which has been linked to neuroprotection $(22-24,27)$ and regulation of the choline transporter activity at the neuromuscular junction (34). The SNCA protein has been linked to impairment of MT-dependent transport in PD models (11-13). CHGB and NRG1 have been linked to motoneuron degeneration and survival $(25,26)$. CHGB, NRG1, sAPP $\alpha$, and SNCA have been previously reported to be released extracellularly $(22-25,28-31)$.

To confirm that the effects of nocodazole are on transport kinetics, rather than protein metabolism, we next isolated cortical synaptic vesicles (Supplemental Figure 2). Anti-synaptophysin antibody staining was used to confirm the isolation of synaptic vesicles from nocodazole-treated and vehicle-treated control mice (Supplemental Figure 2A). The relative abundance of CHGB and NRG1 proteins in cortical synaptic vesicles was not different in nocodazole-treated compared with vehicle-treated control mice, as detected by Western blotting (Supplemental Figure 2B), consistent with unchanged pool sizes and production rates of these proteins. However, pulse ${ }^{2} \mathrm{H}_{2} \mathrm{O}$ labeling revealed a significant delay in the time of disappearance of vesicular ${ }^{2} \mathrm{H}-\mathrm{CHGB}$ and ${ }^{2} \mathrm{H}-\mathrm{NRG} 1$ cargo within the cortical axons of nocodazole- compared with vehicle-treated mice (Supplemental Figure 2C). These results were consistent with concomitant delays in time of appearance we observed for these ${ }^{2} \mathrm{H}$-labeled cargo molecules in CSF in the absence of altered protein concentrations or synthesis rates (Figure 1B).
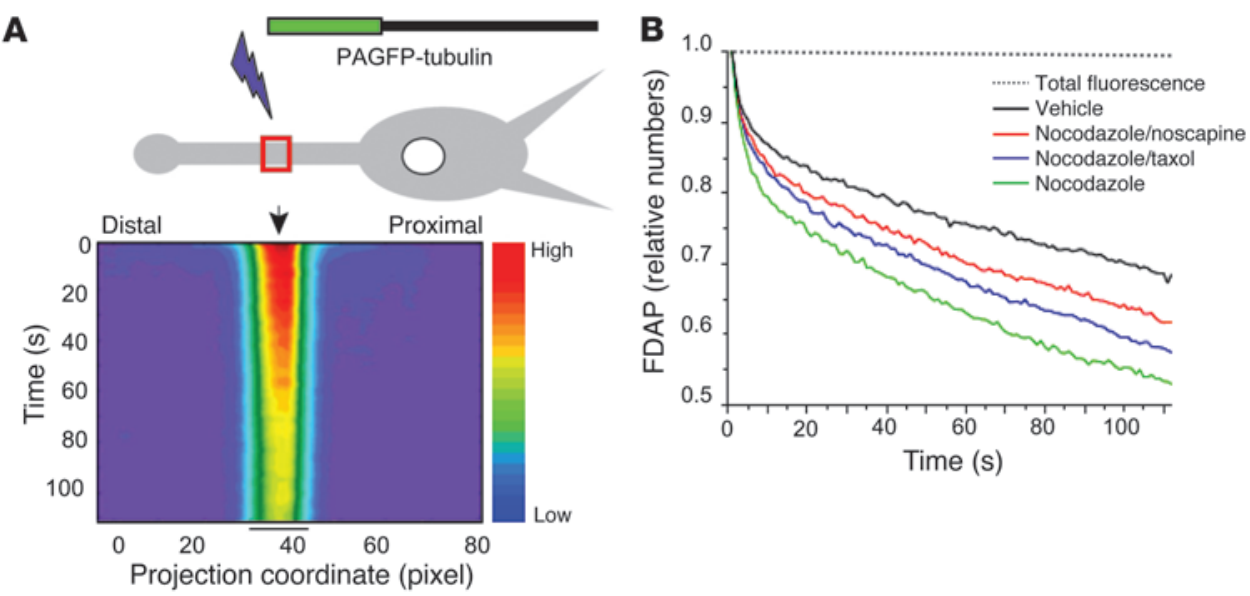

Figure 2

Noscapine and taxol partially reverse nocodazole-induced MT disassembly in living cells. (A) Measurement of FDAP to determine MT dynamics in neuronal processes. PC12 cells were transiently transfected to express PAGFP-tagged tubulin, neuronally differentiated and focally irradiated with an UV laser in the middle of a process. FDAP, as an indicator for the ratio of soluble to polymerized tubulin, was determined in the activation spot, as indicated in the color-coded filled contour plots of 2D intensity function. (B) FDAP plots of cells treated with vehicle $(0.01 \%$ DMSO), nocodazole alone, or nocodazole in combination with taxol or noscapine. Total fluorescence demonstrates photostability of the activated protein. Taxol and noscapine partially reversed the nocodazole-induced increase in FDAP, indicative of MT stabilization by these drugs. FDAP plots show the mean of $n=15-27$ measurements per experimental condition. 

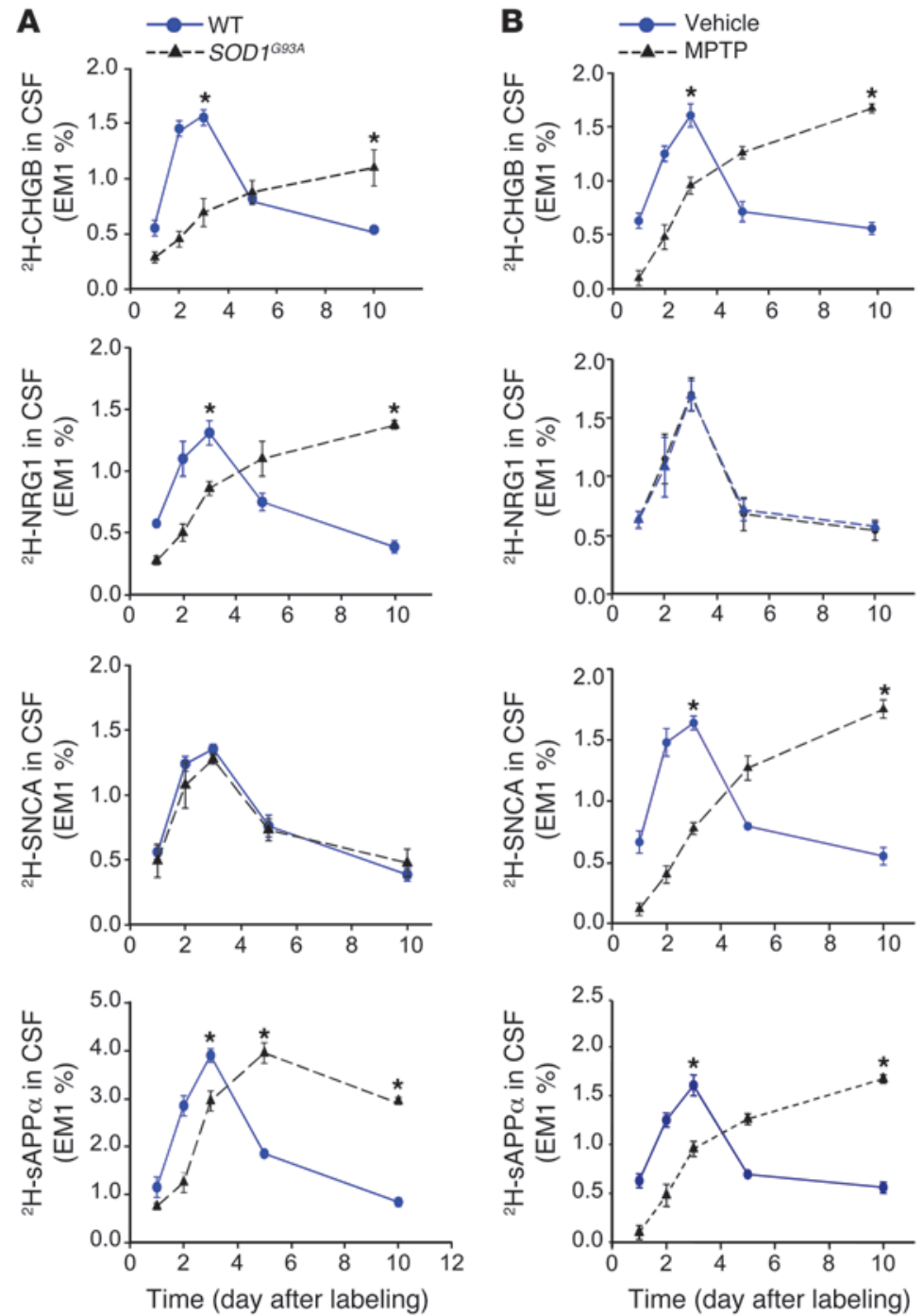

\section{Figure 3}

Differential delays in transport rates of neuronal cargo proteins in symptomatic SOD1G93A mice and MPTP-infused mice. (A) Delays in the time of appearance, $T_{\max }$, and disappearance of ${ }^{2} \mathrm{H}-\mathrm{CHGB},{ }^{2} \mathrm{H}-\mathrm{NRG} 1$, and ${ }^{2} \mathrm{H}-\mathrm{sAPP} \alpha$ were observed in CSF from symptomatic 13-week-old SOD1G93A mice compared with age-matched WT controls ( $n=5$ male and 5 female per time point in duplicate, mean $\pm \mathrm{SD}$ ). The appearance curve of ${ }^{2} \mathrm{H}$-sAPP $\alpha$ suggested less of an effect in delay of secretion rates than that measured for ${ }^{2} \mathrm{H}-\mathrm{NRG} 1$ and ${ }^{2} \mathrm{H}-\mathrm{CHGB}$ in CSF from symptomatic 13-week-old SOD1 ${ }^{\text {G93A }}$ animals. CSF secretion kinetics of ${ }^{2} \mathrm{H}$-SNCA did not change compared with age-matched WT mice. CSF was collected 1, 2, 3, 5, and 10 days after labeling. ${ }^{2} \mathrm{H}$-labeled cargo proteins were sequentially immunoprecipitated and purified to homogeneity from albumin/lg-depleted CSF. ${ }^{*} P<0.001$. (B) Delays in the time of appearance, $T_{\max }$, and disappearance of ${ }^{2} \mathrm{H}-\mathrm{CHGB},{ }^{2} \mathrm{H}-\mathrm{SNCA}$ and ${ }^{2} \mathrm{H}$-sAPP $\alpha$ were observed in CSF from symptomatic MPTP-injected 8-week-old male mice compared with age-matched vehicle controls $(n=10$ per time point in duplicate, mean $\pm S D$ ). CSF secretion kinetics of ${ }^{2} \mathrm{H}-\mathrm{NRG} 1$ did not change compared with age-matched vehicle control mice. Mice received a pulse ${ }^{2} \mathrm{H}_{2} \mathrm{O}$ labeling at 10 days after the last MPTP injection, and CSF was collected from vehicle- and MPTP-injected mice 1, 2, 3, 5, and 10 days after labeling. ${ }^{2} \mathrm{H}$-labeled cargo proteins were sequentially immunoprecipitated and purified to homogeneity from albumin/lg-depleted CSF. ${ }^{\star} P<0.001$.
Noscapine and taxol have been identified as MT-targeting agents (14-16, 35-37). Thus, we next measured their protective effects against nocodazole-induced defects in neuronal transport in vivo. Noscapine and taxol reversed the nocodazole-induced reduction in kinetics of ${ }^{2} \mathrm{H}-\mathrm{CHGB}$ and ${ }^{2} \mathrm{H}-\mathrm{NRG} 1$ in CSF compared with the vehicle control group (Figure 1C). Similar results were obtained for secretion kinetics of ${ }^{2} \mathrm{H}$-sAPP $\alpha$ and ${ }^{2} \mathrm{H}$-SNCA in CSF of taxol- or noscapine-treated mice (Supplemental Figure 1A). Altered CSFbased kinetics of ${ }^{2} \mathrm{H}$-cargo proteins were mirrored by changes in MT turnover in nocodazole-treated mice (Figure 1D). Specifically, ${ }^{2} \mathrm{H}$-label incorporation into TAU- and MAP2-associated (axonal and dendritic, respectively) MTs from hippocampus (Figure 1D) and cortex (Supplemental Figure 1B) was reduced by nocodazole treatment compared with the basal levels found in vehicle-treated mice.

To confirm that taxol or noscapine directly reversed the nocodazole-induced effects on MT polymerization, we also used a live cell imaging assay to determine MT dynamics in living neuronal cells. The method is based on determination of fluorescence decay after photoactivation (FDAP) of photoactivatable GFP-tagged (PAGFP-tagged) tubulin in a spot of a neuronal process (Figure 2A). FDAP is an indicator of the ratio of soluble to polymerized tubulin; as expected, nocodazole treatment increased FDAP compared with vehicle-treated cells (Figure 2B). Both taxol and noscapine partially reversed the effect of nocodazole, suggestive of protective activity on MTs. These findings are consistent with the known MT-stabilizing activities of taxol and noscapine (14-16,35-38) and provide a mechanistic explanation for the restoration of MT-based transport and appearance of ${ }^{2} \mathrm{H}$-labeled cargo proteins in CSF that we observed.

We previously reported that hyperdynamic MTs underlie impairment of axonal transport in $S O D 1^{G 93 A}$ mice (15). Based on these findings, we examined secretion curves of ${ }^{2} \mathrm{H}$-labeled neuronal cargo proteins into CSF of symptomatic $S O D 1^{G 93 A}$ mice (39). Pulse ${ }^{2} \mathrm{H}_{2} \mathrm{O}$ labeling revealed major delays in time of appearance and disappearance for ${ }^{2} \mathrm{H}-\mathrm{CHGB}$ and ${ }^{2} \mathrm{H}-\mathrm{NRG} 1$ in CSF from symptomatic SOD $1^{\mathrm{G} 93 A}$ compared with age-matched WT mice (Figure $3 \mathrm{~A})$. The secretion curve of ${ }^{2} \mathrm{H}$-sAPP $\alpha$ in CSF from symptomatic SOD $1^{G 93 A}$ mice was similar to - but somewhat less affected than those of ${ }^{2} \mathrm{H}-\mathrm{CHGB}$ and ${ }^{2} \mathrm{H}-\mathrm{NRG} 1$, whereas the secretion curve for ${ }^{2} \mathrm{H}-\mathrm{SNCA}$ was no different from WT controls (Figure 3A). These data suggest the existence of altered rates of cargo transport, over time and space, from a broad population of neurons affected in symptomatic SOD $1^{G 93 A}$ mice. 
A
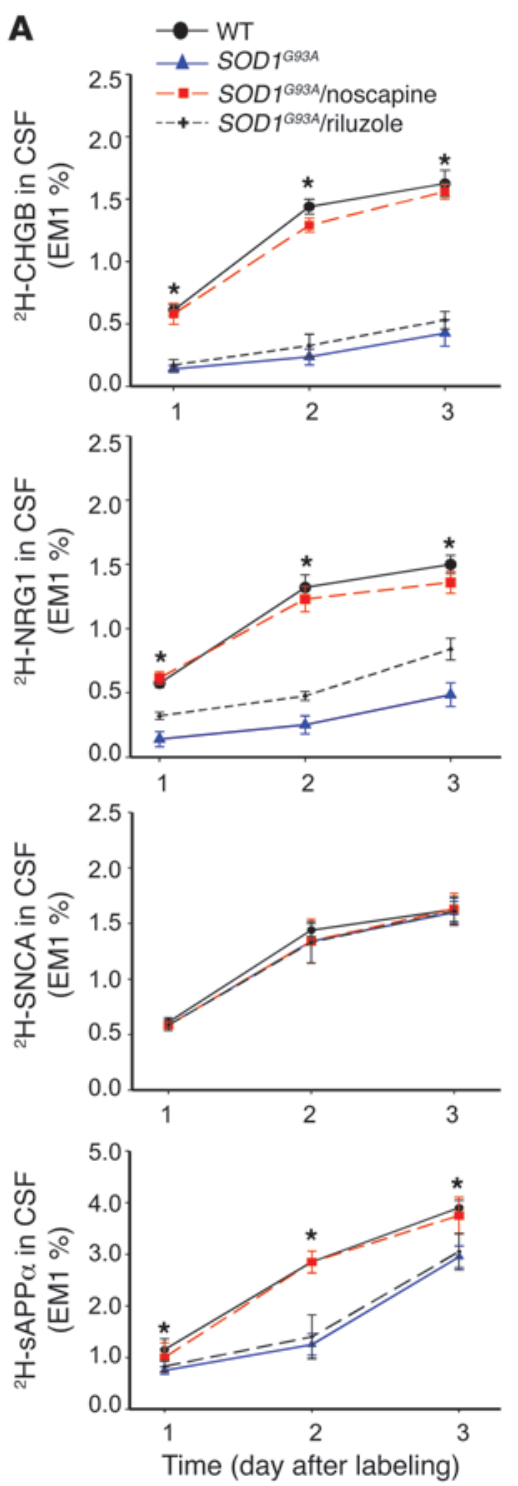
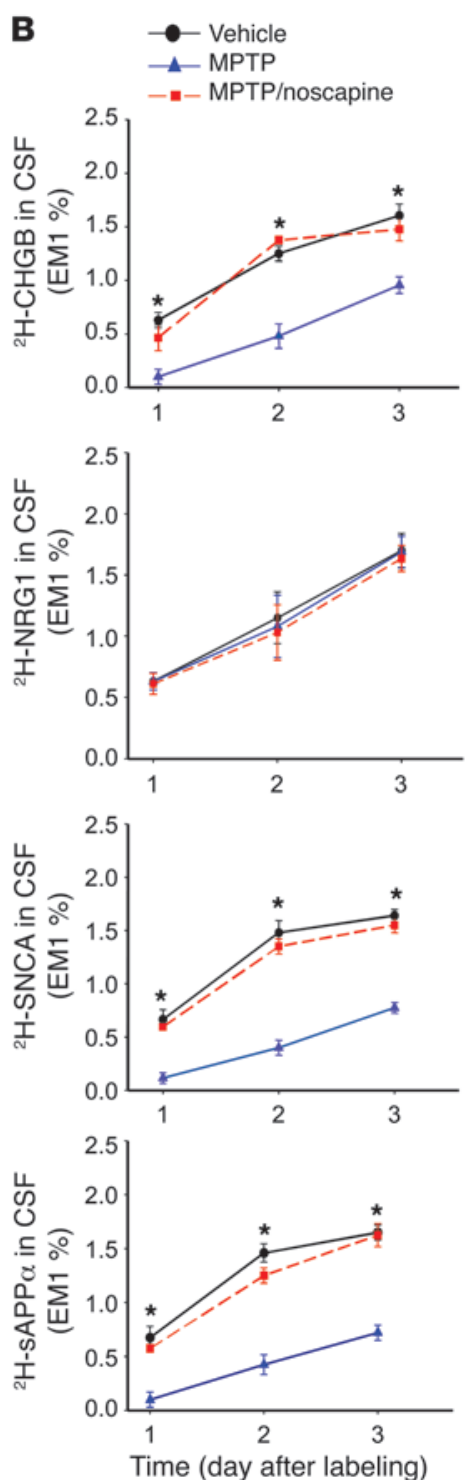

\section{Figure 4}

Noscapine treatment restores transport rates of neuronal cargo proteins in symptomatic SOD1G93A and MPTP-injected mice. (A) CSF-based secretion kinetics (appearance, $T_{\max }$, and disappearance) of 13-weekold ${ }^{2} \mathrm{H}-\mathrm{CHGB},{ }^{2} \mathrm{H}-\mathrm{NRG} 1,{ }^{2} \mathrm{H}-\mathrm{SAPP} \alpha$, and ${ }^{2} \mathrm{H}-\mathrm{SNCA}$ in SOD1 ${ }^{\text {G93A }}$ mice after 3 weeks of treatment with noscapine or riluzole ( $n=5$ males and 5 females per time point in duplicate, mean $\pm S D$ ). Noscapine normalized MTmediated transport rates of ${ }^{2} \mathrm{H}-\mathrm{CHGB},{ }^{2} \mathrm{H}-\mathrm{NRG} 1$, and ${ }^{2} \mathrm{H}$-sAPP $\alpha$ in symptomatic SOD1G93A mice to the levels observed in CSF of age-matched WT controls, whereas riluzole had much less of an effect. Normal kinetics of ${ }^{2} \mathrm{H}$-SNCA was not adversely affected by noscapine treatment. ${ }^{*} P<0.001$. (B) CSF-based secretion kinetics in 8-week-old symptomatic MPTP-injected mice. Treatment with noscapine normalized the kinetics of secretion of ${ }^{2} \mathrm{H}-\mathrm{CHGB},{ }^{2} \mathrm{H}-\mathrm{sAPP} \alpha$, and ${ }^{2} \mathrm{H}-\mathrm{SNCA}(n=10$ males per time point in duplicate, mean \pm SD). Normal kinetics of ${ }^{2} \mathrm{H}-\mathrm{NRG} 1$ were not adversely affected by noscapine treatment. Noscapine was administered 7 days after the last MPTP injection, treatment was for 10 days, and a pulse ${ }^{2} \mathrm{H}_{2} \mathrm{O}$ labeling was administered on the last day of treatment (17 days after the fourth and final MPTP injection). CSF was collected from WT, vehicle control, SOD1G93A, and MPTP mice 1, 2, and 3 days after labeling. ${ }^{2} \mathrm{H}$-labeled cargo proteins were sequentially immunoprecipitated and purified to homogeneity from albumin/lg-depleted CSF. ${ }^{*} P<0.001$.
The environmental toxin MPTP replicates the main biochemical and pathological hallmarks of PD $(32,33)$. Several studies indicate that this toxin exerts its effect by inhibiting mitochondrial complex 1 of substantia nigra dopaminergic neurons $(32,33)$. MPTP also causes loss of dopaminergic neurons in a complex1independent mechanism by increasing phosphorylation of MTassociated TAU and MT dysfunction, which precede mitochondria injury $(13,19)$. Because MPTP-induced MT dysfunction and TAU phosphorylation may affect neuronal transport, we investigated whether MPTP-injected mice show altered CSF kinetics for ${ }^{2} \mathrm{H}$-labeled neuronal cargo proteins. Delayed CSF secretion kinetics of ${ }^{2} \mathrm{H}-\mathrm{CHGB},{ }^{2} \mathrm{H}$-sAPP $\alpha$, and ${ }^{2} \mathrm{H}$-SNCA were observed in MPTP-injected mice compared with vehicle-treated controls (Figure $3 \mathrm{~B}$ ). In contrast, the CSF appearance kinetics of ${ }^{2} \mathrm{H}-\mathrm{NRG} 1$ was identical to those of vehicle-treated controls, unlike those seen in SOD $1^{\text {G93A }}$ mice (Figure 3, A and B). Moreover, in MPTP-injected mice, changes in CSF appearance of ${ }^{2} \mathrm{H}-\mathrm{CHGB},{ }^{2} \mathrm{H}$-sAPP $\alpha$, and ${ }^{2} \mathrm{H}-\mathrm{SNCA}$ were associated with altered MT dynamics in substantia nigra and striatum 3 and 7 days after the last MPTP injection (Supplemental Figure 3A). Hyperdynamic TAU-MTs correlated with an increase in TAU phosphorylation at Ser262 in MPTPinjected mice (Supplemental Table 1), which is uniquely located within one of the MT-binding regions of TAU (40). A similar degree of hyperdynamicity was observed in these brain regions and MT populations isolated from transgenic mice expressing human A53T mutant SNCA on a Snca-null background (Supplemental Figure 3B and ref. 41).

We previously reported that reduction of hyperdynamic MTs by noscapine resulted in recovery of axonal transport, increased motoneuron survival, delayed symptoms, and life extension in SOD $1^{G 93 A}$ mice (15). Based on these findings, we next examined the effects of noscapine and the drug riluzole, an agent approved clinically for the treatment of ALS, on alterations of MT-based transport in symptomatic SOD1 $1^{G 93 A}$ mice, based on the appearance of ${ }^{2} \mathrm{H}$-labeled neuronal cargo proteins in CSF. Treatment with noscapine normalized CSF kinetics of affected neuronal cargo (i.e., ${ }^{2} \mathrm{H}-\mathrm{CHGB},{ }^{2} \mathrm{H}-\mathrm{NRG} 1$, and ${ }^{2} \mathrm{H}$-sAPP $\alpha$ ) without adversely affecting the normal kinetics of ${ }^{2} \mathrm{H}-\mathrm{SNCA}$, whereas riluzole had no significant effects on kinetics of any cargo molecules (Figure 4A). 


\begin{tabular}{|c|c|c|}
\hline & $\begin{array}{l}\text { PD patients } \\
(n=12)\end{array}$ & $\begin{array}{l}\text { Non-PD controls } \\
\quad(n=6)\end{array}$ \\
\hline UDPRS PART III score & $19.9 \pm 6.3$ & - \\
\hline Hoehn and Yahr stage & $2.08 \pm 0.27$ & - \\
\hline Consecutive LPs per subject $(n)$ & $1^{A}$ & 4 \\
\hline $\operatorname{Sex}(F / M)$ & $3 / 9$ & $0 / 6$ \\
\hline CSF albumin (g/l) & $0.35 \pm 0.11$ & $0.37 \pm 0.08$ \\
\hline Plasma albumin (g/l) & $41.4 \pm 0.60$ & $41.3 \pm 0.64$ \\
\hline CSF hemoglobin (ng/ml) & $0.51 \pm 0.53$ & $0.50 \pm 0.64$ \\
\hline Total protein $(\mathrm{mg} / \mathrm{ml})$ & $0.44 \pm 0.06$ & $0.40 \pm 0.05$ \\
\hline CHGB (ng/ml) & $7.86 \pm 4.7$ & $19.21 \pm 4.3$ \\
\hline SNCA (ng/ml) & $1.32 \pm 3.2$ & $2.58 \pm 4.1$ \\
\hline $\mathrm{sAPP} \alpha(\mathrm{ng} / \mathrm{ml})$ & $118.3 \pm 5.4$ & $100.1 \pm 6.2$ \\
\hline NRG1 (ng/ml) & $8.33 \pm 1.93$ & $14.27 \pm 2.9$ \\
\hline
\end{tabular}

Values represent mean $\pm S D$. F, female; $M$, male; UDPRS, unified PD rating scale. 3 non-PD control subjects were HIV infected, albeit virtually suppressed; 1 PD patient was excluded because the subject failed to meet study criteria. PD patients' ages at LP were $62.3 \pm 0.94$ years $(n=3), 66.7 \pm 1.69$ years $(n=3), 58 \pm 0.70$ years $(n=4)$, and $78.5 \pm$ 3.5 years $(n=2)$; non-PD controls' ages at LP were $36.5 \pm 2.5$ years $(n=2), 51.0 \pm 2.0$ years $(n=2)$, and $60.5 \pm 0.5$ years $(n=2)$. Total protein, CHGB, SNCA, SAPP $\alpha$, and NRG1 were measured in albumin/ Ig-depleted CSF. All CSF samples had normal total protein concentrations and normal CSF plasma albumin levels (which correlate with low hemoglobin levels in CSF), as measured by ELISA. The percentage of secreted cargo proteins removed from CSF samples by preincubation with antibody beads was $85 \%$ for each, as quantitated by ELISA. A1 PD subject volunteered for 4 LPs.

Similarly, in MPTP-injected mice, treatment with noscapine normalized CSF kinetics of affected neuronal cargo (i.e., ${ }^{2} \mathrm{H}-\mathrm{CHGB},{ }^{2} \mathrm{H}-\mathrm{SNCA}$, and ${ }^{2} \mathrm{H}$-sAPP $\alpha$ ) without adversely affecting the normal kinetics of ${ }^{2} \mathrm{H}-\mathrm{NRG} 1$ (Figure 4B); reduced hyperdynamic MTs (Supplemental Figure 3A); and resulted in symptom reversal (Supplemental Figure 4, A-C).

Alterations in CSF kinetics of neuronal ${ }^{2} \mathrm{H}$-cargo proteins were not caused by general defects in CSF protein clearance, as the replacement rate (half-life) of total CSF proteins was identical in symptomatic SOD1 ${ }^{G 93 A}$, MPTP-injected, and control mice (Supplemental Figure 5, A and B).

It is also possible that generic suppression of neurotransmission may reduce the release of the cargo proteins in the CSF. However, the altered cargo kinetics observed were induced by treatment with a MT-depolymerizing agent and reversed by treatment with a MT-stabilizing agent (36-38).

In summary, these results demonstrate, first, that measurement of appearance/disappearance kinetics of pulse-labeled neuronal cargo proteins into CSF represents a biomarker for monitoring axonal transport defects and, second, that treatments targeting MT dynamics can improve altered cargo transport kinetics in symptomatic murine models of neurodegeneration.

Altered kinetics of neuronal transport in CSF of PD patients. Next, we asked whether this approach could reveal differences in patients with neurodegenerative disease compared with non-PD control subjects. The technique for measurement of neuronal transport kinetics in human subjects involves a simple outpatient procedure consisting of daily oral intake of 3 drinks of ${ }^{2} \mathrm{H}_{2} \mathrm{O}(3 \times 50 \mathrm{ml}$ of $70 \%$ ${ }^{2} \mathrm{H}_{2} \mathrm{O}$ ) for a week (the pulse labeling period), followed by 1 or more
LPs to collect CSF and collection of blood samples to measure body ${ }^{2} \mathrm{H}_{2} \mathrm{O}$ enrichments. ${ }^{2} \mathrm{H}_{2} \mathrm{O}$ has been extensively administered to humans for over 60 years without evidence of toxicities (42) and has no serious adverse effects in animal systems until it reaches levels greater than $20 \%$ of total body water - more than an order of magnitude greater than the levels achieved in these subjects. The labeling protocol of a 7-day pulse dose of ${ }^{2} \mathrm{H}_{2} \mathrm{O}$ was given to 6 non-PD controls and 12 PD subjects (see Table 2 for clinical details and biochemical assessment in body fluids).

The 6 non-PD control subjects showed a minimal lag period between changes in ${ }^{2} \mathrm{H}_{2} \mathrm{O}$ enrichment in body water (the precursor pool) and ${ }^{2} \mathrm{H}$-cargo appearance (the product) (Figure 5, A and B), indicative of rapid transit of newly synthesized cargo proteins from the cellular site of synthesis to the site of sampling. PD patients exhibited markedly slower transport kinetics of ${ }^{2} \mathrm{H}$-cargo, characterized by a pattern of strikingly prolonged release into the CSF (Figure 6, A and B). Specifically all 12 PD subjects showed persistence of ${ }^{2} \mathrm{H}-\mathrm{CHGB},{ }^{2} \mathrm{H}$-sAPP $\alpha$, and ${ }^{2} \mathrm{H}-\mathrm{SNCA}$ in $\mathrm{CSF}$ at days $15,21,22,23$, and 38 , instead of a return to baseline enrichments in parallel with the fall in body ${ }^{2} \mathrm{H}_{2} \mathrm{O}$ enrichment, as observed in the non-PD control subjects. In 1 PD subject, PD6084, repeated LPs were performed at days 3, 9, 21, and 38, which clearly showed delayed appearance in addition to persistence of ${ }^{2} \mathrm{H}$-cargo in CSF (Figure 6B). Stated differently, the ${ }^{2} \mathrm{H}$-cargo present in CSF during the ${ }^{2} \mathrm{H}_{2} \mathrm{O}$ label decay phase from days $15-38$ in control subjects had enrichments that reflected almost exactly the $T_{\max }$ possible at the low body ${ }^{2} \mathrm{H}_{2} \mathrm{O}$ enrichments present at the date of CSF sampling, whereas the ${ }^{2} \mathrm{H}$-cargo in $\mathrm{PD}$ patients had enrichments much greater than the possible $T_{\max }$ if the cargo molecules had been synthesized on that day. Therefore, the cargo must have been synthesized when the body ${ }^{2} \mathrm{H}_{2} \mathrm{O}$ enrichments were higher (i.e., at least several days previously).

These results were consistent with a defect in axonal transport. Interestingly, the secretion curves for ${ }^{2} \mathrm{H}-\mathrm{NRG} 1$ in the PD subjects were similar to those observed in controls (Figure 6B), suggestive of altered rates of cargo transport, as reflected in CSF from a distinct degeneration of neuronal subpopulations affected in PD patients.

The persistence of ${ }^{2} \mathrm{H}$-cargo proteins in CSF of PD patients could not be explained by defective protein clearance from CSF, since no significant changes in the turnover rate (half-life) of total CSF proteins were observed in the PD patients (Supplemental Figure 5C).

A previous radiolabeling study of axonal transport (43) showed slowing with aging, particularly for slow axonal transport of SNCA. It is therefore conceivable that the transport abnormalities in the PD patients were simply a result of their older age, not of pathology. Despite the difficulties in obtaining a large control cohort of elderly volunteers for routine LP, 4 controls that were close in age to the PD patients (Table 2) did not show altered cargo transport kinetics compared with the younger controls (Figure $5 \mathrm{~B})$. Thus, aging per se appears unlikely to explain the changes in CSF secretion rates of cargo molecules observed in PD patients.

In summary, these results demonstrated that CSF kinetic biomarkers of axonal transport were translatable into human subjects and may be useful to assess the status of neurodegeneration and potentially to monitor therapeutic modulation.

\section{Discussion}

Biomarkers reflecting neuronal dysfunction prior to neuronal cell death would be particularly useful for guiding therapeutic interventions. Previous studies have shown that striking changes in MT 


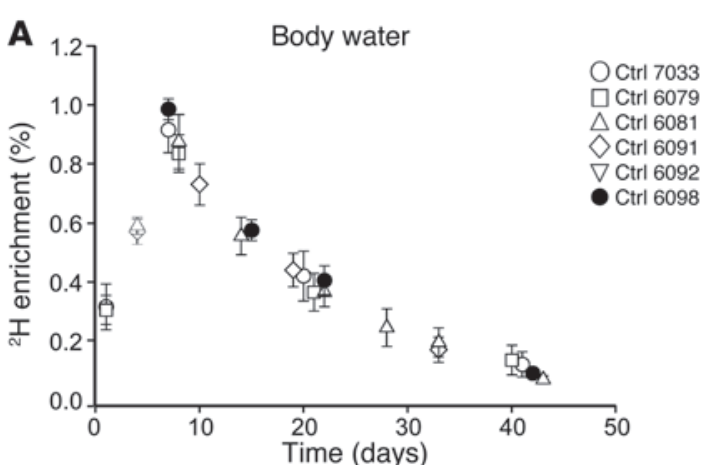

B
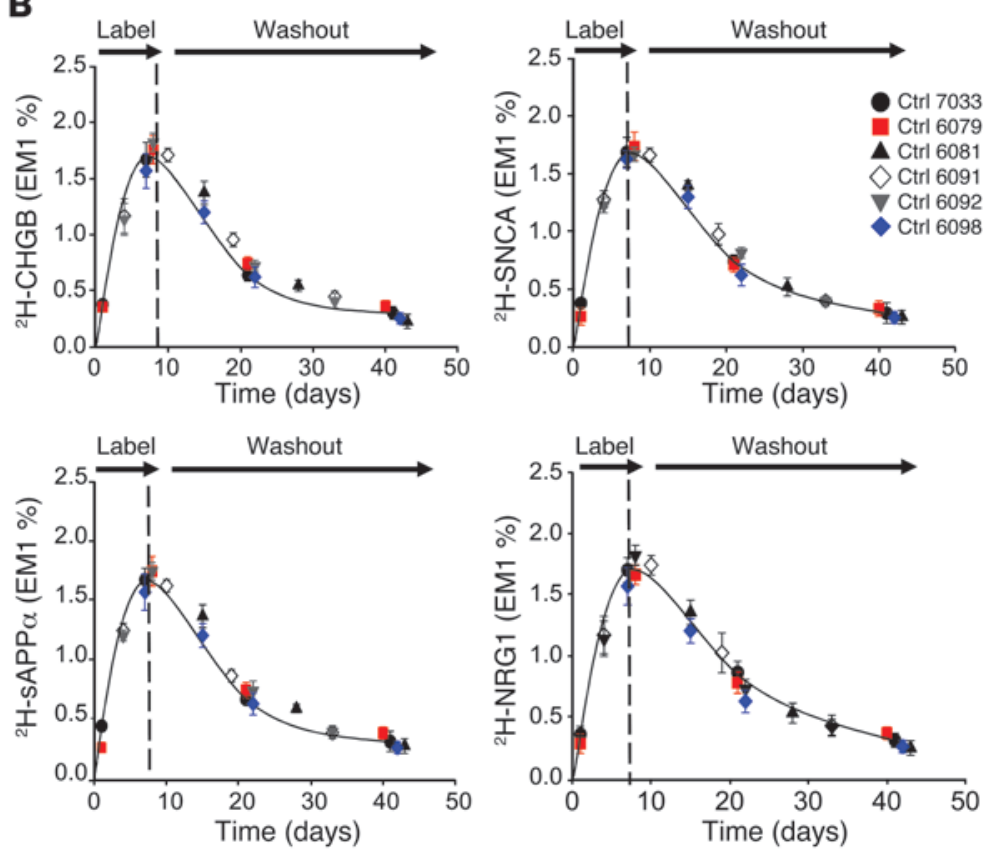

\section{Figure 5}

Transport rates of neuronal cargo proteins in CSF of nonPD volunteers. (A) Decline in plasma body water ${ }^{2} \mathrm{H}$ enrichment in control (Ctrl) volunteers. Body ${ }^{2} \mathrm{H}_{2} \mathrm{O}$ enrichments peaked at day 7 , then died away with a half-life of approximately 7 days, consistent with known turnover rate of body water in humans. (B) Enrichment curves in CSF cargo proteins from 6 control non-PD volunteers (mean \pm SD, generated by technical replicates of repeated sample preparations and analyses). 4 LPs were conducted in 6 controls (days 2-15, 21-43) after beginning ${ }^{2} \mathrm{H}_{2} \mathrm{O}$ administration (7-day labeling protocol). The line represents the curve fit of the data. ${ }^{2} \mathrm{H}$-labeled cargo proteins were sequentially immunoprecipitated and purified to homogeneity from albu$\mathrm{min} / \mathrm{lg}$-depleted CSF. turnover, which in turn affects kinetics of axonal transport, are early and progressive events in preclinical models of neurodegeneration $(2-8,11,12,15,19)$. However, translating from animal models to human patients the hypothesis that impaired trafficking of cargo is associated with neurodegeneration required a method by which to capture kinetics of transport by sampling CSF.

To our knowledge, the in vivo stable isotope method described here represents the first direct exploration of altered kinetics of axonal transport by sampling CSF in animals and humans with neurodegeneration. We demonstrated in pharmacological, ALS, and PD mouse models an association between altered cargo transport and altered MT turnover and showed that reduction of MT turnover with MT-targeting agents restored MT-based transport while delaying or reversing disease end points. Together with other studies $(15-17,19,38)$, these results raise the possibility that neuronal dysfunction caused by hyperdynamic MTs and altered MT-based transport represents a therapeutic target.

The results obtained using the ${ }^{2} \mathrm{H}_{2} \mathrm{O}$ pulse labeling method provided a quantitative measure of how long it takes for an ${ }^{2} \mathrm{H}$-labeled cargo, synthesized during the label exposure period, to travel from the place of synthesis (cell body) to the distal regions of a neuron to be released into the EF and ultimately reach the CSF (Figure 7). Thus, this method is not designed to measure the absolute pro- duction rate of cargo proteins by the cell or the absolute rate of release into the CSF. The steady-state concentration in CSF of a transported protein is a function of the rate of production $(\mathrm{mg} / \mathrm{h})$ and the rate constant of removal (fraction removed/h). At steady state, the absolute amount of a protein removed from CSF must equal the amount released into CSF, whether the protein concentration in CSF is low, normal, or high. Accordingly, transport kinetics of ${ }^{2} \mathrm{H}$-cargo proteins, revealed by kinetics of appearance in and disappearance from CSF, have the same interpretation regardless of CSF concentrations (Figure 7). For example, NRG1 and CHGB concentrations were both markedly reduced in CSF of MPTP-injected mice and PD subjects, but the times of appearance in and disappearance from CSF of NRG1 were unchanged from those of controls, whereas these were much delayed for CHGB (Figure 7 and Table 2). Another example is SNCA, altered levels of which have been observed in PD patients (44). SNCA in the CSF does not by itself cause neurodegeneration, however, whereas impaired axonal transport of SNCA reflects a functionally significant perturbation from homeostasis and may be an important feature of the pathogenesis of neurodegenerative diseases. An alteration in general clearance (turnover) of proteins from CSF could alter kinetics of labeled proteins in CSF, but this was not observed in murine ALS and PD models or in PD human subjects. 

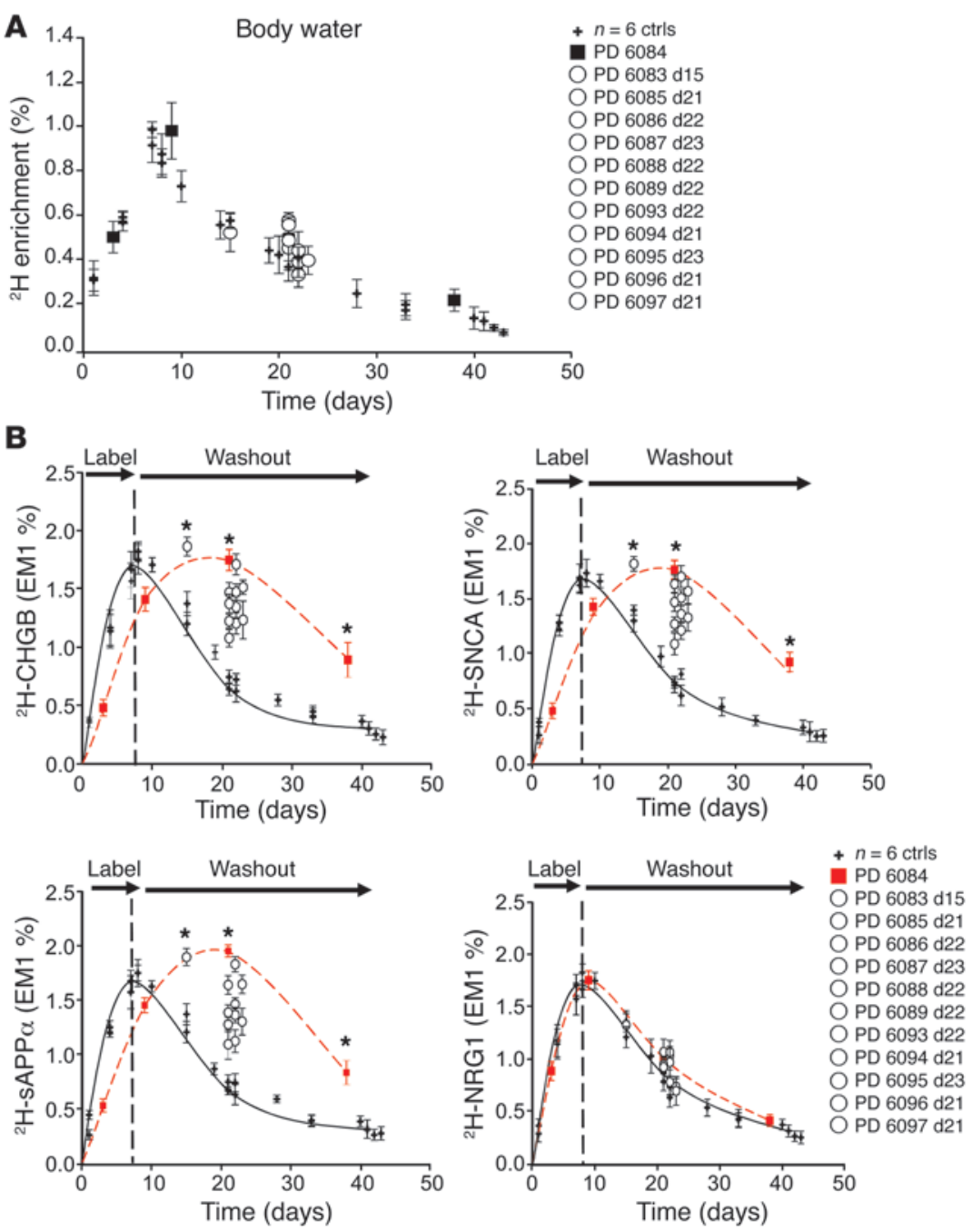

\section{Figure 6}

Differential delays in transport rates of neuronal cargo proteins in CSF of PD subjects. (A) Decline in plasma body water ${ }^{2} \mathrm{H}$ enrichment in control nonPD volunteers and PD subjects. Body ${ }^{2} \mathrm{H}_{2} \mathrm{O}$ enrichments peaked at day 7 , then decayed with a halflife of approximately 7 days, consistent with known turnover rate of body water in humans. (B) 4 LPs were conducted in 1 PD patient (PD 6084; days 3 , 9,21 , and 38 ), and a single LP was conducted in 11 PD subjects (days $15,21,22$, or 23 ) after starting ${ }^{2} \mathrm{H}_{2} \mathrm{O}$ administration (7-day labeling protocol). Delays in the time of appearance of neuronal ${ }^{2} \mathrm{H}-\mathrm{CHGB}$, ${ }^{2} \mathrm{H}-\mathrm{SNCA}$, and ${ }^{2} \mathrm{H}$-sAPP $\alpha$, but not that of ${ }^{2} \mathrm{H}-\mathrm{NRG} 1$, were observed in CSF from PD subjects compared with 6 control volunteers (mean $\pm S D$, generated by technical replicates of repeated sample preparations and analyses). Solid and dashed lines represent curve fits of the data for controls and PD volunteers, respectively. ${ }^{2} \mathrm{H}$-labeled cargo proteins were sequentially immunoprecipitated and purified to homogeneity from albumin/lg-depleted CSF. ${ }^{\star} P<0.001$.
In considering these data, it is useful to distinguish the fundamental information provided by isotopic measurements of flux through a pathway (e.g., MT-based transport of cargo) from the information provided by measurement of protein levels in CSF (e.g., by ELISA).

Sampling of CSF does not allow direct characterization of time to release of cargo proteins from axons of different lengths, but the kinetic labeling techniques capture integrated rates of cargo transport, differing in time and space, from a broad population of neurons affected by the disease. Indeed, preclinical and clinical results revealed discrete secretion curves of cargo proteins affected by neurodegeneration (e.g., CHGB, sAPP $\alpha$, and SNCA versus NRG1 in MPTP-injected mice and PD subjects), which suggests the existence of kinetically distinct degeneration of neuronal subpopulations. The ability to assign specific cargo proteins to specific classes of neurons would be potentially powerful, but this knowledge is not yet available. These observations were not apparent from standard measurements of protein concentrations in CSF, but required the use of kinetic labeling techniques.

It is likely that the concentrations of CSF proteins (e.g., amyloid- $\beta$ and TAU) will be useful in some diseases, whereas cargo protein transport rates will be more informative for the state or course of other illnesses. One important distinction relates to cell viability. Neurons must be viable in order for proteins to be synthesized and then transported and released into CSF as ${ }^{2} \mathrm{H}$-labeled cargo. In the case of dying neurons, old cargo proteins may be released, but they will not be ${ }^{2} \mathrm{H}$-labeled and will not interfere with in vivo measurements of MT-based neuronal transport, in contrast to the potential confounding effects of cell death on protein levels in CSF.

To our knowledge, this is the first direct in vivo measurement of axonal transport of cargo proteins in experimental animals and humans with neurodegeneration. This approach may be useful as a biochemical record of neurodegenerative or reparative processes in diseases such as PD and ALS. Importantly, the clinical data reported here showed that these biomarkers distinguished PD patients from controls and may provide a powerful tool to select animal models, evaluate treatment (e.g., therapies addressing MT dynamics, as demonstrated in this study), and understand patient variability.

\section{Methods}

Animal studies and ${ }^{2} \mathrm{H}_{2} \mathrm{O}$ labeling. Transgenic mice carrying the human SOD1 gene with a G93A mutation and WT littermate mice were purchased from Jackson Laboratories. Transgenic mice carrying the human A53T mutant SNCA cDNA driven by the mouse prion protein promoter homozygosed on a Snca-null background [Snca ${ }^{t m I N b m} ; \operatorname{Tg}\left(\operatorname{Prnp}-S N C A^{*} A 53 T\right)$ mice] (41) were bred in house at the National Genome Research Institute/NIH (NHGRI/ $\mathrm{NIH}$ ) facility. FVB/N and $129 \mathrm{~S} 6$ (Taconic), the 2 background strains that 


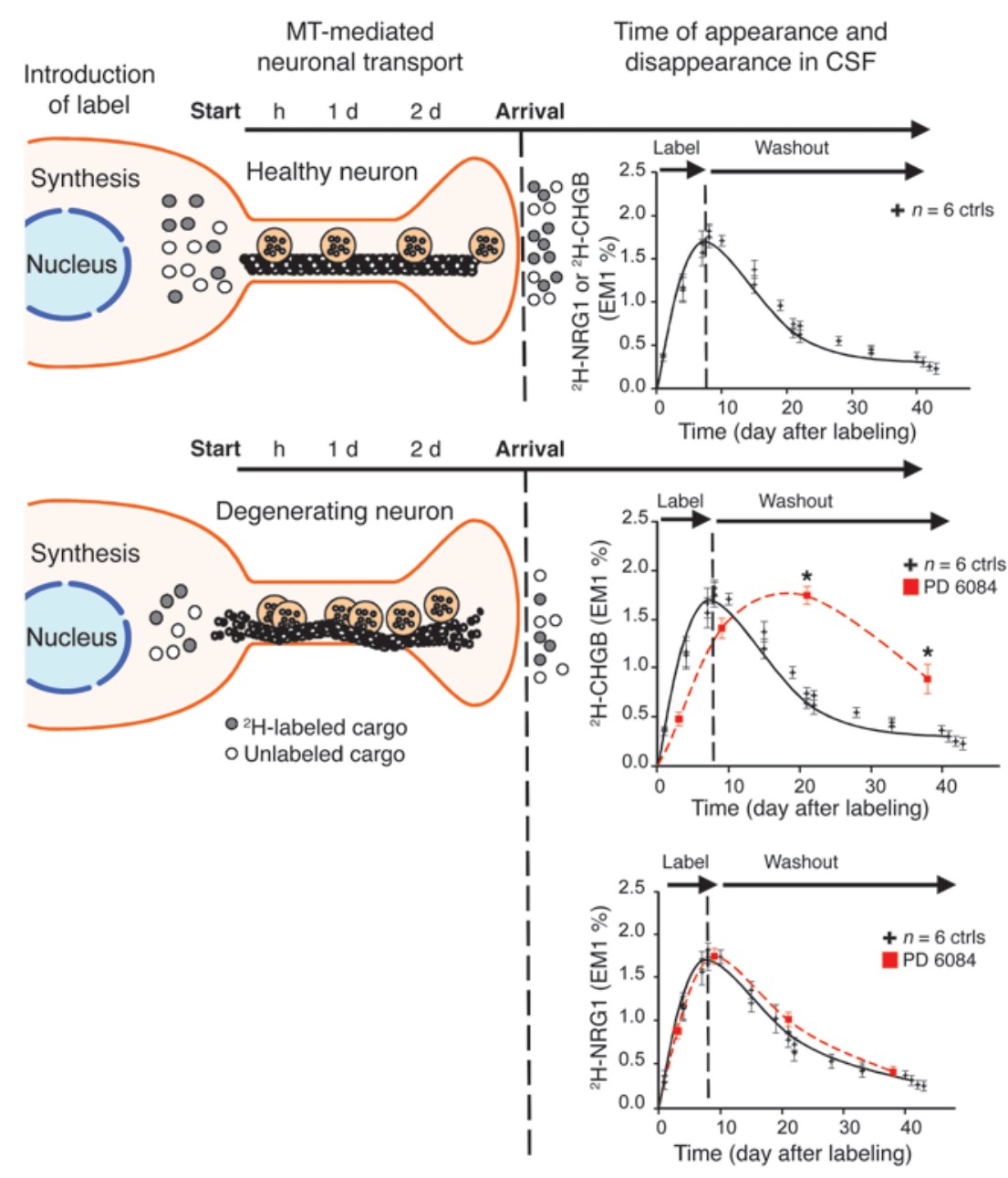

\section{Figure 7}

Model and kinetic interpretation of transport dynamics of released cargo proteins in CSF. Newly synthesized cargo proteins destined for secretion travel from the cell body of neurons, where they are primarily produced, to the nerve terminal, where they are released into the CSF. MT-based transport kinetics are based on the timing of appearance and disappearance of newly synthesized ${ }^{2} \mathrm{H}$-labeled neuronal cargo proteins in CSF, after in vivo metabolic labeling. The differences between kinetics of appearance in and disappearance from CSF of ${ }^{2} \mathrm{H}-\mathrm{CHGB}$ and ${ }^{2} \mathrm{H}-\mathrm{NRG} 1$ in controls and PD subjects are summarized. Solid and dashed lines represent the curve fits of the data for controls and PD volunteers, respectively. CHGB and NRG1 concentrations were both markedly reduced in CSF of PD subjects (see Table 2). Delayed kinetics of appearance in and disappearance from CSF of ${ }^{2} \mathrm{H}$-labeled cargo proteins were independent of CSF protein concentrations. are mixed in the $S n c a^{t m 1 N b m} ; \operatorname{Tg}\left(\operatorname{Prnp}-S N C A^{*} A 53 T\right)$ mice, were bred in house at KineMed to generate mixed-background control mice. Intracerebroventricular cannulated (ICVC) C57BL/6BomTac mice (Taconic), males aged 10 weeks, received 6- $\mu$ l infusions of either nocodazole (30 nM in 20\% Captisol; CyDex Pharmaceuticals) or nocodazole with noscapine (10 nM; Sigma-Aldrich) and nocodazole with taxol (10 nM; Sigma-Aldrich) over a period of 6 minutes. Control animals were infused with $6 \mu$ of $20 \%$ Captisol. For ICVC infusion, the internalization tip of a sterile cannula was stereotaxically placed in the lateral ventricle (anterior/posterior, $-1.0 \mathrm{~mm}$; medial/lateral, $+1.0 \mathrm{~mm}$, left side; dorsal/ventral, -2.0 to $2.5 \mathrm{~mm}$ ). In the studies with mice expressing ALS-linked mutant SOD1 ${ }^{G 93 A}$, noscapine (Sigma-Aldrich) was injected intraperitoneally at $200 \mathrm{mg} / \mathrm{kg} / \mathrm{d}$, and riluzole was given in diet, with the final drug dose computed to be $44 \mathrm{mg} / \mathrm{kg} / \mathrm{d}$. Treatment of SOD $1^{\mathrm{G} 93 A}$ mice was begun at the symptomatic age of 10 weeks and continued until 13 weeks, when mice were sacrificed for collection of CSF and comparison with untreated age-matched WT mice. For MPTP intoxication, MPTP (Sigma-Aldrich) or vehicle (saline) was injected over the course of 1 day at 2-hour intervals (4 single intraperitoneal injections of $20 \mathrm{mg} / \mathrm{kg}$ MPTP or vehicle) in C57BL/6 males aged 8 weeks. Noscapine was injected intraperitoneally at $200 \mathrm{mg} / \mathrm{kg} / \mathrm{d}$. Treatment of MPTP-injected mice began 7 days after the 4 MPTP injections and continued for 10 days, at which time mice were sacrificed for collection of CSF and comparison with untreated age-matched control mice. All animals tolerated the treatments well, and there were no differences in body weight among animals of different groups. For CSF kinetics of transport, mice received a pulse ${ }^{2} \mathrm{H}_{2} \mathrm{O}$ labeling consisting of an intraperitoneal bolus of $30-35 \mathrm{ml} / \mathrm{kg}^{2} \mathrm{H}_{2} \mathrm{O}$ (99.9\%; Isotec-Sigma) containing $0.9 \% \mathrm{w} / \mathrm{v} \mathrm{NaCl}$. CSF collection, storage procedures, and total protein isolation are described in Supplemental Methods. For MT dynamics, mice received an intraperitoneal priming bolus of $30-35 \mathrm{ml} / \mathrm{kg}^{2} \mathrm{H}_{2} \mathrm{O}\left(99.9 \mathrm{~mol} \mathrm{\%}{ }^{2} \mathrm{H}_{2} \mathrm{O}\right)$ containing $0.9 \% \mathrm{wt} / \mathrm{vol} \mathrm{NaCl}$ and then maintained on $8 \%{ }^{2} \mathrm{H}_{2} \mathrm{O}$ in drinking water (to allow for dilution of label by metabolic water) for 24 hours prior to sacrifice. Both labeling protocols result in $4 \%-5 \%$ body water ${ }^{2} \mathrm{H}$ enrichment (14-17). Measurement of ${ }^{2} \mathrm{H}_{2} \mathrm{O}$ enrichment in body water is described in Supplemental Methods. All animals were housed in a controlled temperature and humidity environment and maintained on a 12-hour light/dark cycle, with access to food and water provided ad libitum.

Cell culture and transient transfection. Chemicals, cell culture media, and supplements were obtained from Sigma-Aldrich and Invitrogen; culture plates and dishes were from Thermo Fisher Scientific unless stated otherwise. pIREShyg2-PAGFP- $\alpha$ Tubulin was constructed by Tulu et al. (45) and obtained from Addgene (Addgene plasmid 12296). PC12 cells were cultured in serum-DMEM as described previously (46). $10^{5}$ cells were plated on 35-mm polylysine- and collagen-coated glass-bottomed culture dishes. Cells were transiently transfected with $2.5 \mu \mathrm{g}$ pIREShyg2-PAGFP- $\alpha$ Tubulin using Lipofectamine 2000 and OPTIMEM. Cells were neuronally differentiated in DMEM containing $1 \% \mathrm{v} / \mathrm{v}$ serum and $100 \mathrm{ng} / \mathrm{ml} 7 \mathrm{~S}$ mouse NGF (Alomone Labs) for 4 days with 1 medium exchange after 2 days. Cells 
were pretreated with drugs ( $30 \mathrm{nM}$ nocodazole, alone or in combination with $10 \mathrm{nM}$ taxol or $10 \mathrm{nM}$ noscapine) or carrier alone (0.01\% DMSO) for 30 minutes and imaged within 1 hour.

Photoactivation and live cell imaging. Live cell imaging was performed on a laser scanning microscope (Eclipse TE2000-U inverted; Nikon) equipped with argon $(488 \mathrm{~nm})$ and blue diode $(405 \mathrm{~nm})$ lasers and EZ-C1 software. The microscope was enclosed in an incubation chamber maintained at $37^{\circ} \mathrm{C}$ and $5 \% \mathrm{CO}_{2}$ (Solent Scientific Limited). PAGFP-expressing cells were visualized with a Fluor $\times 60$ (NA 1.4) UV-corrected (VC) objective lens. Photoactivation in a $5-\mu \mathrm{m}$ diameter spot in the middle of a process was performed with the 405-nm blue diode. Automated image acquisition was essentially performed as described previously for 112 seconds at a frequency of $1 \mathrm{frame} / \mathrm{s}$ and a resolution of $256 \times 256$ pixels $(47,48)$.

Image analysis. Images were analyzed using Fiji (General Public License). A circular region of interest (ROI) of 13 pixels in diameter was defined to mark the activation area, and the sum of gray values of the pixels in the ROI was calculated for every frame. All values were normalized to the value of the first frame after activation. Data were plotted as color-coded filled contour plots of $2 \mathrm{D}$ intensity function using MatLab (MathWorks Inc.) and as FDAP plots (48).

Isolation and purification of CSF secreted proteins. CSF samples were first immunodepleted using the albumin/IgG removal kit (Fisher Scientific) and then fractionated by sequential binding to CHGB (Abcam), NRG1 (H-210; Santa Cruz Biotechnology), sAPP $\alpha$ (2B3; IBL America), and SNCA (Cell Signaling) antibody beads. Each eluted cargo protein was purified to homogeneity by reverse-phase chromatography on a Gemini-NX-5 $\mu \mathrm{m}$ C18 Column (Phenomenex) using a $20 \%-40 \%$ acetonitrile in $0.1 \%$ TFA gradient over 25 minutes at $1.5 \mathrm{ml} / \mathrm{min}$. ELISA tests were used according to the manufacturer's instructions to determine concentrations of CHGB, NRG1, SNCA (Uscn Life Science), and sAPP $\alpha$ (IBL International) in CSF (Table 1), and the identity of each protein was confirmed by mass spectrometry (see Supplemental Methods).

Isolation of tubulin dimers and MTs. In brief, mice were anesthetized by inhalation of isoflurane $(2 \%-2.5 \% \mathrm{~atm})$ in $2-\mathrm{min} / 1 \mathrm{O}_{2}$, followed by cardiac puncture and thoracectomy. Cardiac puncture was performed to collect blood for body water measurements of ${ }^{2} \mathrm{H}_{2} \mathrm{O}$ enrichments. Brains were rapidly removed and washed in MT-stabilizing buffer (MSB) containing protease and phosphatase inhibitor cocktails (at concentrations recommended by the manufacturer, Calbiochem); the striatum and substantia nigra were dissected and gently homogenized in MSB. Tubulin dimers and TAU-, MAP2-associated, and cold stable MTs were isolated and purified to homogeneity as previously described (14-17). A sandwich ELISA was used to measure TAU phosphorylation at Ser262 in striatal and substantia nigra total lysates of MPTP-injected mice compared with vehicle controls (Santa Cruz Biotechnology).

Human study design and ${ }^{2} \mathrm{H}_{2} \mathrm{O}$ labeling. The study group consisted of symptomatic PD patients, all on standard anti-PD medications, and 6 non-PD volunteers. PD diagnosis was based on clinical evaluation and UK Parkinson's Disease Society Brain Bank Clinical Diagnostic Criteria (49). Unified PD Rating Scale, PART III, and Hoehn and Yahr scores were obtained for each subject (Table 2). None of the patients had any atypical features or evidence of more widespread neurological disease. The 6 non-PD controls included 3 healthy volunteers and 3 individuals with well-treated HIV infection; the latter were on combination antiretroviral therapy with longterm plasma viral suppression, had normal CSF white blood cell counts, and CSF/plasma albumin ratios indicated absence of local inflammation or abnormal blood-brain barrier permeability. Eligible subjects were instructed to drink $50 \mathrm{ml}$ of $70 \%{ }^{2} \mathrm{H}_{2} \mathrm{O}$ (Isotec-Sigma) 3 times per day, leaving at least 3 hours between doses, for a period of 7 consecutive days. Compliance to the experimental protocol was monitored by the clinical staff through collection of blood plasma samples for body water enrichment. 4 LPs were conducted in 6 controls and 1 PD patient (days 2-15 and 21-43), and a single LP was conducted in the other 11 PD subjects (days 15, 21, 22, or 23), after starting ${ }^{2} \mathrm{H}_{2} \mathrm{O}$ administration (7 days labeling protocol).

Processing of cargo proteins for GC/MS analysis. Purified cargo proteins were hydrolyzed by treatment with $6 \mathrm{~N} \mathrm{HCl}$ for 16 hours at $110^{\circ} \mathrm{C}$. Proteinderived amino acids were derivatized to pentafluorobenzyl derivatives, and ${ }^{2} \mathrm{H}$ incorporation in alanine released from total vesicular proteins was measured by GC/MS, as described elsewhere (50). ${ }^{2} \mathrm{H}$ enrichment was calculated as the percent increase over the natural abundance of alanine derivative present as the $(M+1)$ mass isotopomer (EM1) (50).

Calculations. The fraction of newly synthesized alanine in each sample was calculated as the ratio of the measured EM1 value to the maximal value expected at the measured body water enrichment, which was calculated by mass isotopomer distribution analysis, as described in detail elsewhere (50). This value was taken to represent fractional protein synthesis.

Statistics. The statistical significance of CSF secretion rates of selected cargo molecules was assessed by 1-way ANOVA with Tukey post-hoc testing. A $P$ value less than 0.05 was considered statistically significant. Software for statistics included SigmaStat3.0 and Microsoft Excel 2003.

Study approval. All animal procedures were approved by KineMed Animal Care and Use Committee. Snca ${ }^{t m 1 N b m} ; \operatorname{Tg}($ Prnp-SNCA*A53T) mice were bred in accordance with protocols approved by the NHGRI/NIH Institutional Animal Care and Use Committee. All human studies were approved by the UCSF Committee on Human Research, and written informed consent was obtained from all participants before study entry. Clinical work was performed at the UCSF CTSI Clinical Research Center (CRC) of the San Francisco General Hospital.

\section{Acknowledgments}

We thank Benedikt Niewidok for help with performing the photoactivation assay. The authors thank all the patients and other human subjects who participated in this study. The clinical study was supported by a grant from The Michael J. Fox Foundation for Parkinson's Research to P. Fanara. This project was also supported by NIH/NCRR UCSF-CTSI grant UL1 RR024131.

Received for publication May 1, 2012, and accepted in revised form July 12, 2012.

Address correspondence to: Patrizia Fanara, KineMed Inc., 5980 Horton Street, Suite 470, Emeryville, California 94608, USA. Phone: 510.655.6525; Fax: 510.655.6506; E-mail: pfanara@kinemed.com.
1. Thoenen H, Sendtner M. Neurotrophins: From enthusiastic expectations through sobering experiences to rational therapeutic approaches. Nat Neurosci. 2002;5(suppl):1046-1050.

2. Chevalier-Larsen E, Holzbaur EL. Axonal transport and neurodegenerative disease. Biochim Biophys Acta. 2006;1762(11-12):1094-108

3. Roy S, Zhang BV, Lee M-Y, Trojanowski JQ. Axonal transport defects: a common theme in neurodegenerative diseases. Acta Neuropathol. 2005;109(1):5-13.
4. El-Kadi M, Soura V, Hafezparast M. Defective axonal transport in motor neuron disease. J Neurosci Res. 2007;85(12):2557-2566.

5. Gunawardena S, et al. Disruption of axonal transport by loss of huntingtin or expression of pathogenic polyQ proteins in Drosophila. Neuron. 2003;40(1):25-40.

6. Her LS, Goldstein LS. Enhanced sensitivity of striatal neurons to axonal transport defects induced by mutant huntingtin. J Neurosci. 2008;
28(50):13662-12672.

7. Collard JF, Cote F, Julien JP. Defective axonal transport in a transgenic mouse model of amyotrophic lateral sclerosis. Nature. 1995;375(6526):61-64.

8. Williamson TL, Cleveland DW. Slowing of axonal transport is a very early event in the toxicity of ALSlinked SOD1 mutants to motor neurons. Nat Neurosci. 1999;2(1):50-56.

9. Kabuta T, et al. Familial amyotrophic lateral sclerosis-linked mutant SOD1 aberrantly inter- 
acts with tubulin. Biochem Biophy Res Commun. 2009;387(1):121-126

10. Strey CW, et al. Dysregulation of stathmin, a microtubule-destabilizing protein, and up-regulation of Hsp25, Hsp27, and the antioxidant peroxiredoxin 6 in a mouse model of familial amyotrophic lateral sclerosis. Am J Pathol. 2004;165(5):1701-1718.

11. Lee HJ, Khoshaghideh F, Lee S, Lee SJ. Impairment of microtubule-dependent trafficking by overexpression of alpha-synuclein. Eur J Neurosci. 2006;24(11):3153-3162.

12. Saha AR, et al. Parkinson's disease a-synuclein mutations exhibit defective axonal transport in culture neurons. J Cell Sci. 2004;117(7):1017-1024.

13. Qureshi HY, Paudel HK. Parkinsonian neurotoxin 1-methyl-4-phenyl-1,2,3,6-tetrahydropyridine (MPTP) and $\alpha$-synuclein mutations promote Tau protein phosphorylation at Ser262 and destabilize microtubule cytoskeleton in vitro. J Biol Chem. 2011;286(7):5055-5068.

14. Fanara $\mathrm{P}$, et al. In vivo measurement of microtubule dynamics using stable isotope labeling with heavy water. Effect of taxanes. J Biol Chem. 2004; 279(48):49940-49947.

15. Fanara $P$, et al. Stabilization of hyperdynamic microtubule is neuroprotective in ALS.J Biol Chem. 2007 ; 282(32):23465-23472.

16. Fanara $\mathrm{P}$, et al. Changes in microtubule turnover accompany synaptic plasticity and memory formation in response to contextual fear conditioning in mice. Neuroscience. 2010;168(1):167-178.

17. Barten DM, et al. Hyperdynamic microtubules, cognitive deficits and pathology are improved in tau transgenic mice with low doses of the microtubule stabilizing agent, BMS-241027. J Neurosci. 2012;32(21):7137-7145.

18. Guzik BW, Goldstein LS. Microtubule-dependent transport in neurons: steps towards an understanding of regulation, function and dysfunction. Curr Opin Cell Biol. 2004;16(4):443-450.

19. Cartelli D, Ronchi C, Maggioni MG, Rodighiero S, Gavini E, Cappelletti G. Microtubule dysfunction precedes transport impairment and mitochondria damage in $\mathrm{MPP}+$ induced neurodegeneration. J Neurochem. 2010;115(1):247-258.

20. Goldstein LS, Yang Z. Microtubule-based transport systems in neurons: the roles of kinesins and dyneins. Annu Rev Neurosci. 2000;23:39-71.

21. Johanson CE, Stopa EG, McMillan PN. The bloodcerebrospinal fluid barrier: structure and functional significance. Methods Mol Biol. 2011;686:101-13.

22. Thouvenot E, et al. Enhanced detection of CNS cell secretome in plasma protein-depleted cerebrospinal fluid. J Proteome Res. 2008;7(10):5509-4421.
23. Kaether C, Skehel P, Dotti CG. Axonal membrane proteins are transported in distinct carriers: a two-color video microscopy study in cultured hippocampal neurons. Mol Biol Cell. 2000; 11(4):1213-1224

24. Thinakaran G, Koo EH. Amyloid precursor protein trafficking, processing, and function. J Biol Chem. 2008;283(44):29615-29619.

25. Urushitani M, Sik A, Sakurai T, Nukina N, Takahashi R, Julien JP. Chromogranin-mediated secretion of mutant superoxide dismutase proteins linked to amyotrophic lateral sclerosis. Nat Neurosci. 2006;9(1):108-118.

26. Ricart $\mathrm{K}$, et al. Interactions between $\beta$-neuregulin and neurotrophins in motor neuron apoptosis. J Neurochem. 2006;97(1):222-233.

27. Steinacker $\mathrm{P}$, et al. Soluble beta-amyloid precursor protein is related to disease progression and amyotrophic lateral sclerosis. PLoS One. 2011;6(8):e23600.

28. Pankonin MS, Sohi J, Kamholz J, Loeb JA. Differential distribution of neuregulin in human brain and spinal fluid. Brain Res. 2009;1258:1-11.

29. Borghi R, et al. Full length alpha-synuclein is present in cerebrospinal fluid from Parkinson's disease and normal subjects. Neurosci Lett. 2000;287(1):65-67.

30. Lee HJ, Patel S, Lee SJ. Intravesicular localization and exocytosis of alpha synuclein and its aggregates. J Neurosci. 2005;25(25):6016-6024.

31 . Hansen $C$, et al. $\alpha$-Synuclein propagates from mouse brain to grafted dopaminergic neurons and seeds aggregation in cultured human cells. J Clin Invest. 2011;121(2):715-725.

32. Hisahara S, Shimohma S. Toxin-induced and genetic animal models of Parkinson's disease. Parkinsons Dis. 2010;2011:951709.

33. Smeyne RJ, Jackson-Lewis V. The MPTP model of Parkinson's disease. Brain Res Mol Brain Res. 2005; 134(1):57-66

34. Wang B, Yang L, Wang Z, Zheng H. Amyloid precursor protein mediates presynaptic localization and activity of the high-affinity choline transporter. Proc Natl Acad Sci US A. 2007;104(35):14140-14145.

35. Jordan MA, Wilson L. Microtubules as a target for anticancer drugs. Nat Rev Cancer. 2004;4(4):253-265.

36. Zho J, Panda D, Landen JW, Wilson L, Joshi HC. Minor alteration of microtubule dynamics causes loss of tension across kinetochore pairs and activates the spindle checkpoint. J Biol Chem. 2002; 277(19):17200-17208.

37. Marx KA, Zhou T, Montrone A, McIntosh D Braunhunt SJ. A comparative study of the cytoskeleton binding drugs nocodazole and taxol with the mammalian cell quartz crystal miroblalance biosensor: different dynamic response and energy dis- sipation effects. Anal Biochem. 2007;361(1):77-92.

38. Zhang B, et al. Microtubule-binding drugs offset tau sequestration by stabilizing microtubules and reversing fast axonal transport deficits in a tauopathy model. Proc Natl Acad Sci US A. 2005;102(1):227-231.

39. Gurney ME. Transgenic animal models of familial amyotrophic lateral sclerosis. J Neurol. 1997; 224(2):15-20

40. Drewes G, et al. Microtubule-associated protein/ microtubule affinity-regulating kinase (p110mark). A novel protein kinase that regulates tau-microtubule interactions and dynamics instability by phosphorylation at the Alzheimer-specific site serine 262. J Biol Chem. 1995;270(13):7679-7688.

41. Cabin DE, Gispert-Sanchez S, Murphy D, Auburger G, Myers RR, Nussbaum RL. Exacerbated synucleinopathy in mice expressing A53T SNCA on a Snca null background. Neurobiol Aging. 2005;26(1):25-35.

42. Hellerstein MK, et al. Subpopulations of long-lived and short lived T cells in advanced HIV-1 infection. J Clin Invest. 2003;112(6):956-966.

43. Li W, Hoffman PN, Stirling W, Price DL, Lee MK. Axonal transport of human alpha-synuclein slows with aging but is not affected by familial Parkinson's disease-linked mutations. J Neurochem. 2004;88(2):401- 410

44. Mollenbauer B, Locascio JJ, Schulz-Schaeffer W, Sixel-Döring F, Trenkwalder C, Schlossmacher MG. $\alpha$-Synuclein and tau concentrations in cerebrospinal fluid of patient presenting with parkinsonism: a cohort study. Lancet Neurol. 2011;10(3):230-240.

45. Tulu US, Rusan NM, Wadsworth P. Peripheral, non-centrosome-associated microtubules contribute to spindle formation in centrosome-containing cells. Curr Biol. 2003;13(21):1894-1899.

46. Fath T, Eidenmüller J, Brandt R. Tau-mediated cytotoxicity in a pseudohyperphosphorylation model of Alzheimer's disease. J Neurosci. 2002; 22(22):9733-9741.

47. Weissmann C, Reyher HJ, Gauthier A, Steinhoff HJ, Junge W, Brandt R. Microtubule binding and trapping at the tip of neurites regulate tau motion in living neurons. Traffic. 2009;10(11):1655-1668.

48. Gauthier-Kemper A, Weissmann C, Reyher HJ, Brandt R. Monitoring cytoskeletal dynamics in living neurons using fluorescence photoactivation. Methods Enzymol. 2012;505:3-21.

49. Hughes AJ, Daniel SE, Kilford L, Lees AJ. Accuracy of clinical diagnosis of idiopathic Parkinson's disease: a clinico-pathological study of 100 cases. J Neurol Neurosurg Psychiatry. 1992;55(3):181-184.

50 . Busch R, et al. Measurement of protein turnover rates by heavy water labeling of nonessential amino acids. Biochim Biophys Acta. 2006;1760(5):730-44. 